\section{Outstanding Business Reference Sources 2012}

BRASS Business Reference Sources Committee: contributing members: Susan Hurst, selections editor; Becky Smith, nominations coordinator and chair; John Burns, Craig Eich, Valerie Freeman, Gene Hayworth, Van Houlson, Michael Matos, Glenn McGuigan, Michael Oppenheim, Joan Plungis, and Penny Scott.

For information contact Susan Hurst, Business Librarian, Miami University, Oxford, OH 45056; email: hurstsj@muohio.edu ach year, the Business Reference Sources Committee of BRASS selects the outstanding business reference sources published since May of the previous year. This year, the committee reviewed thirty entries; of these, three were designated as "Outstanding," two were selected as "Noteworthy," while a sixth was designated as a significant new edition. To qualify for the award, the title must meet the conventional definition of reference: a work compiled specifically to supply information on a certain subject or group of subjects in a form that will facilitate its ease of use. With print reference materials being used less heavily in most cases, these works stood out based on their content, quality, and utility. The works are examined for the following: authority and reputation of the publisher, author, or editor; accuracy; appropriate bibliography; organization; comprehensiveness; value of the content; currency; unique addition; ease of use for the intended purpose; quality and accuracy of index; and quality and usefulness of graphics and illustrations. Each year, more electronic reference titles are published. Additional criteria for electronic reference titles are accuracy of links, search features, stability of content, and graphic design. Works selected must be suitable for mediumto large-size academic and public libraries.

\section{OUTSTANDING TITLES}

AMA Handbook of Financial Risk Management. By John J. Hampton. New York: American Management Association, 2011. 303 p. \$75 hardcover (ISBN: 978-0-8144-1744-7). \$75 single-user access electronic book, $\$ 112.50$ multiple-user access (ISBN: 978-0-8144-1745-4)

John J. Hampton, professor of business at St. Peter's College, former executive director of the Risk and Insurance Management Society and principal in the Princeton Consulting Group, has written an exceptionally clear and well-organized source on financial risk management. The AMA Handbook of Financial Risk Management was selected for the 2012 Innovation Award from Business Insurance Magazine, which recognizes leadership, inventiveness, and ingenuity in products and services designed for professional risk managers.

Risk is everywhere when operating a business. Hampton mentions a large, unnamed corporation that identified 2,100 business unit risks and 800 common risks across all business units. ${ }^{1}$ However, this work's scope is limited to about a dozen of the most frequently encountered types of financial risk. These include investment risk, in which a company fails to earn a return or loses its invested capital; liquidity risk, when no one 
wants to buy a company's securities or other assets of value; cash flow risk, when a company has to stop an activity that did not yield enough to pay its obligations; debt risk, when a business cannot repay the interest and loan balance on money it borrowed; credit risk, which can involve a loan of money to a party who cannot repay it, or not being paid for goods sold to another; valuation risk, when property bought at the top of the market loses a significant amount of its value; information technology risk, which occurs when a company loses market share to its competitors because it did not keep up with new technologies; and hedging risk, when the cost paid for raw materials soars rather than dropping as anticipated. ${ }^{2}$

The author's stated intention was to create a reference book comprising a dictionary, an encyclopedia, and a "cookbook," by which he meant directions for applying techniques to achieve results and outcomes. ${ }^{3}$ It succeeds in all these dimensions. Most chapters include appendixes that summarize the chapter's key concepts using data and tables, which will be particularly helpful for reference purposes. For example, the chapter on valuation of business combinations concludes with the appendix, "How to Assess the Value of a Complex Potential Acquisition Candidate."

Topics addressed are categorizing financial risks; accounting, cash flow, and budget exposures; analyzing operating risks (profit planning, leverage, financial analysis); relationship of risk and return (time value of money; risk and required return); nature of a capital investment decision (capital budgeting cash flows, capital budgeting returns); and factors that affect the value of a firm (valuation of common stock, capital structure of the firm, valuation of business combinations).

The book intersperses definitions and discussions of concepts with formulas, graphics, tables, mini-case studies, and other material that illustrate and reinforce the text. For example, a 2006 Lehman Brothers' balance sheet and a concise excerpt from the business press accompany the discussion of balance sheet manipulation in chapter 2, "Risks from Financial Accounting," and graphs show the effect of a rising debt-equity relationship in chapter 13, "Capital Structure of the Firm."

Other recently published titles on this subject, such as the third edition of Christoffersen's Elements of Financial Risk Management and Coleman's Quantitative Risk Management: A Practical Guide to Financial Risk, tend to be highly mathematical, or textbooks, or both. Hampton's book is truly a pragmatic handbook, offering quantitative guidance and formulas, but written in a style accessible to those with or without a financial background. It is also general enough to be useful to those working in a variety of industries. -Joan Plungis, University of Dayton, Dayton, Ohio

Encyclopedia of Municipal Bonds: A Reference Guide to Market Events, Structures, Dynamics, and Investment Knowledge. By Joe Mysak. Hoboken, NJ: Bloomberg, 2012. 215 p. Print: \$95. (ISBN: 978-1-118-00675-7).

This is an unusual "encyclopedia" in several ways. One is that it is a relatively brief single volume work. Second, all entries were compiled by a single author (albeit an expert in the bond field since 1981). Another feature is the specificity, with all entries tied to the somewhat narrow field of municipal bonds. However, this last part is what makes the book so successful (indeed "outstanding"). While the author maintains the focus on municipal bonds throughout, he does so with a broad enough scope so that the work touches on many areas you wouldn't normally associate with the topic (examples include computers, house museums, and Indian tribes). Overall the terms selected vary from the mundane (Par) to the esoteric (Ultra Vires) to the obscure (William F. G. Shanks-started the "Daily Bond Buyer" paper in 1891). The author titles all of this "Muniland" and he endeavors to explain its intricacies and idiosyncrasies throughout the work. He begins naturally enough in the introduction, where he provides a brief overview of the bond market, as well as his own experiences covering some of the more controversial aspects of the last few years, (particularly swaps and yield burning), as a reporter and columnist for the "Daily Bond Buyer" (note that both of these terms are well covered in the encyclopedia itself).

Within the volume, all entries are listed alphabetically and thus there is no index. However, there is a table of contents, which lists all the entries within each letter heading. The book is up-to-date and covers current topics like the Dodd-Frank Act and the pension underfunding scandal. The entries themselves are written in layman's terms and are descriptive, easy to read, and well explained. In the introduction the author mentions that he is telling "stories" and this is another one of the key reasons for the success of this work. The entries often read more like a brief story or article on a topic, rather than a standard jargon-filled dictionary definition. Entries range in length from quite brief (a sentence or two) to several pages, for the broader topics such as Orange County, CA or insurance. The author also notes the importance of being able to locate and access primary source materials, and he walks the talk with a majority of the entries including a list of sources. Many subjects have "see also" listings as well, tying in related terms and topics. One drawback though is that this title is primarily available in print, although it can be accessed on a Kindle. An online edition would be welcome for several reasons; one of which being that related terms or topics could be linked for added functionality. Overall though, this is a well-written book by an author that has spent the last thirty years covering the municipal market. It a rare reference title, especially on such a specific topic, which is readable and interesting (and understandable) to those outside of the field. Much to the author's credit, that is the case for this work. This is recommended both for academic libraries as well as public libraries with strong business and investing collections. -Susan Hurst, Miami University, Oxford, Ohio

Encyclopedia of Sports Management and Marketing. Ed. Linda E. Swayne and Mark Dodds. Thousand Oaks, CA: SAGE Publications, 2011. 4 volumes, 1858 p. Hardback: \$695 (ISBN: 978-1-4129-7382-3). E-book: $\$ 869$ for multiple user access from SAGE and Gale (ISBN: 978-1-4129-9415-6).

Sports management is a popular field of study that 


\section{FROM COMMITTEES OF RUSA}

applies business practices to the sports industry. Programs are proliferating at higher education institutions: the $\mathrm{Na}$ tional Association for Sport Management and Marketing (NASSM) lists 334 American and 57 non-US colleges and universities that offer this interdisciplinary specialization. ${ }^{4}$ The Encyclopedia of Sports Management and Marketing is an essential reference resource for libraries that support undergraduate sports management programs, and a good choice for large public libraries serving high school students, those working in or aspiring to careers in sports-related fields, and serious sports fans.

Edited by Linda E. Swayne, director of the MBA in Sports Marketing and Management program at the University of North Carolina, Charlotte, and Mark Dodds, a veteran of the sports marketing industry who now teaches sports marketing and sports law at the State University of New York (SUNY) College at Cortland, the 834 signed entries are arranged alphabetically by title in four print volumes. Contributors include academics, independent scholars, and experts from the sport industry. Most are from the United States, but New Zealand, Australia, the UK, France, Mexico, Canada, India, South Africa, Germany, Austria, Egypt, South Korea, Greece, Japan, Switzerland, and Hong Kong also are represented. Most entries are 3-5 pages long, and color photographs illustrate many of the articles. Each concludes with "see also" references and a further readings list that includes books, popular and scholarly articles, and websites.

The topics included in the Encyclopedia of Sports Management and Marketing reflect integral component areas in sport management degree programs, as defined by the Commission on Sport Management Accreditation (COSMA): social, psychological and international foundations of sport; management, including sport leadership, operations/venue/event management, and sport governance; ethics in sport management; sport marketing; finance, accounting, and economics; legal aspects of sport; and an integrative experience such as an internship or other capstone experience. ${ }^{5}$ The topically arranged Reader's Guide at the beginning of volume 1 and the complete list of articles provided in each volume will help users locate all material pertinent to their interests, as will the excellent index with ample cross-referencing that concludes volume 4 .

Among the more than 100 management topics in the encyclopedia are Human Resources Management, Professional Team Valuation, and Crisis Management, plus dozens of entries pertinent to event management and facilities management. Arena Funding-Public/Private, Demand Elasticity and Inelasticity in Sports, Break-Even Analysis, and Capital Investment are examples of entries relating to the economics and financing of sport. Social marketing and Internet/ online/web/mobile marketing topics are well represented, as are advertising, news media, pricing, and promotions. Legal topics include Copyright Law and Sports, Dispute Resolution/Arbitration, Gender Equity, and Media Content Rights Fees. The encyclopedia also includes entries for almost 140 US and Canadian teams.
Additional features include a chronology of important events in sports history from 1403 forward and a glossary. Of particular note are the six appendixes containing the full text of several major pieces of legislation, such as the Sports Agent Responsibility and Trust Act, the Anabolic Steroid Abuse Act, and Title IX. Available in print and online, the Encyclopedia of Sports Management and Marketing's selection of topics, clear and accessible language, excellent cross-references and index, and valuable appendixes will make it an often-consulted addition to library reference collections.-Joan Plungis, University of Dayton, Dayton, Ohio

\section{OTHER NOTEWORTHY TITLES}

Progressive Careers. By Dave Anderson and Laurence Shatkin. St. Paul, MN: JIST, 2011. 4 vols. 1329 p. print \$230 (ISBN: 978-1-59357-768-1)

This encyclopedia is organized into four volumes that describe green careers, high-growth careers, nontraditional careers, and STEM careers. They represent occupations that tend to be in demand. For example the fifty-seven occupations in high-growth careers have at least a 20 percent growth projection based on the Bureau of Labor Statistics. Nontraditional careers and high-growth careers are technical and vocational occupations. All the volumes have good introductions that discuss issues such as job growth versus job openings, competition, and the kinds of interests, skills, and personalities that fit each area.

The layout is excellent and includes charts, graphs, photos, bulleted lists. Some entries have a feature called "Consider This" to emphasize employment possibilities that would otherwise be overlooked. Entries have sections that are either bullet points or summaries. "Just the Facts" outlines earnings, job growth, annual openings, and education and training requirements. "While At Work" describes different occupations and specializations. "Job Fit" has a list of personality types, skills, and work styles. "Working Conditions" gives insights into what is expected for a job. "What's Required" goes into detail about educational requirements, training programs, licensing, exams, and subject expertise. "Employment" covers job prospects and earnings. "Related Jobs" and "How to Learn More" are minimal but do include professional associations. Depending on the volume, there are additional sections for each career. For example, the volume on high-growth careers has a section called "Why It's Hot" about the larger picture about jobs in demand. In the green careers volume, a similar paragraph is called "Going Green."

Organizing careers into volumes that have a theme leads to some duplication. For example the career of medical scientist appears both in the STEM careers and high-growth careers volumes. All volumes will be of interest to public libraries, and colleges and two-year programs. Universities and larger institutions, career offices and libraries will likely find "Green Careers" or "STEM Careers" more useful. —Van Houlson, University of Minnesota, Minneapolis, Minnesota 


\section{SIGNIFICANT NEW EDITION}

Business: The Ultimate Resource. London: A\&C Black, 2011. 1607 p. $\$ 75$ (ISBN: 978-14081-2811-4).

The third edition of this massive business reference book continues to offer an excellent overview of the many facets of business information. This work stands apart from similar "all-in-one" types of business handbooks (such as The Portable MBA Desk Reference published by Wiley) because it focuses more upon business theories and concepts than formulas or simple definitions. While it does have a lengthy dictionary, the impressive parts of the book are the brief capsules of the great works of management theory included in both the "Management Library" section and the "Business Thinkers" section. Therefore the reader will have not only a summary of two of Michael Porter's great works (Competitive Advantage of Nations and Competitive Strategy) in the library section, but also a brief (two-page) overview of Porter's ideas throughout his career. A curious distraction is that the "Management Library" arranges the items alphabetically by title, while the "Business Thinkers" section arranges entries alphabetically by name. Thankfully the index references both works in each section.
While the second edition was published in the prerecession year of 2006, this third edition of 2011 includes marked changes that reflect the new economic reality. For example, new essays in the "Action List" section include "Marketing Yourself in a Diminished Market," "Reapplying for your Own Job," and "Using the Downturn to Up-skill." Hopefully future editions will not require the inclusion of such essays as a mirror of the times. Other changes from the second edition appear to be mostly cosmetic, with enhanced, bolder font for readability. The work is a powerful, and reasonably priced, reference tool that should be in all business collections. - Glenn McGuigan, Penn State, Harrisburg, Pennsylvania

\section{References}

1. John J. Hampton, AMA Handbook of Financial Risk Management (New York: AMACOM, 2011), 2.

2. Ibid., 1-2.

3. Ibid., xvi.

4. National Association for Sport Management and Marketing, "Sports Management Programs," accessed July 12, 2012, www .nassm.com/InfoAbout/SportMgmtPrograms.

5. Mark Dodds, introduction to Encyclopedia of Sports Management and Marketing, ed. Linda E. Swayne and Mark Dodds, vol. 1 (Thousand Oaks, CA: Sage Reference, 2011), vii-viii. 